\title{
Çok Ölçütlü Karar Verme Yöntemleriyle Hayırsever Kuruluşlarında Verimlilik Analizi
}

\section{Efficiency Analysis in Charity Organizations by Multiple Criteria Decision Making Methods}

\section{Dr. Öğr. Üyesi Aşır Özbek}

Başvuru Tarihi: 18.122015

Kabul Tarihi: 06.06.2017

\section{Öz}

Kâr amacı güden işletmeler gibi sosyal alanlarda hizmet veren Sivil Toplum Kuruluşları da (STK) hizmetlerinin kesintisiz olarak devam etmesi için sürekli olarak kendilerini yenilemeli ve geliştirmelidir. Bu iyileştirme ve dönüşüm sürecini ciddiye alan kuruluşlar, verdikleri hizmetlerde belirli bir standarda ulaşmakta ve faaliyetlerini uzun süre devam ettirebilmektedir. Diğer taraftan kendilerini sürekli olarak iyileştirmeyi önemsemeyen kuruluşlar ise bağış̧̧larının kendilerine verdiği katkıy verimli olarak kullanamadiklarından dolayı zamanla gelir kaybına uğramakta ve devamlilikların sürdürmekte zorluklarla karşılaşmaktadır. Bu nedenlerden dolayı STK'lar da kâr amacı güden işletmeler gibi verimli ve etkin çalışmak durumundadır. STK'lar belirli araliklarla verimlilik analizi yaparak mevcut durumlarını kontrol etmeli ve bu doğrultuda gerekli yapısal ve stratejik kararları zaman geçirmeden almaları gerekmektedir.

Bu çalışma ile 2004 yılından itibaren Kirıkkale'de sosyal alanlarda özelliklede hayır işlerinde hizmet veren «Beşinci Mevsim Yardım Derneğinin» 2005-2014 yılları arasındaki verimliliği analiz edilmiştir. Model iki farklı yöntemin entegre olarak uygulanmasın ve sonuçlarm karşılaştıılmasını öngörmektedir. Bu yöntemler; Veri Zarflama Analizi (VZA) ve Efficiency Analysis Technique With Output Satisficing (EATWOS) tekniklerini içermektedir. Modelde kullanılan girdi ve çıtıtı faktörlerinin ağırlikları puanlama tekniği ile elde edilmiştir. Modelin ilgili STK'ya uygulanması neticesinde 2007 ve 2011 yillarındaki faaliyetlerin diğer yıllara göre daha az verimli geçtiğini söylemek mümkündür.

Anahtar Kelimeler: Sivil Toplum Kuruluşları, Hayırsever Kuruluşları, Verimlilik Analizi, Veri Zarflama Analizi, EATWOS

\begin{abstract}
Not only businesses, but also non-governmental organizations (NGOs) should constantly renew and improve themselves to maintain sustainability in their social services. Those organizations which take this improvement and transformation process seriously can sustain a certain standard and operate for a long term. However, those which do not care about it will have difficulty maintaining their continuity as they will face income loss in time because of the inefficiency in using the donations properly. Therefore, efficiency is as an important issue for NGOs as it is for businesses. That is why it is crucial for an NGO to go through efficiency analysis at certain intervals to see the situation and to make the necessary structural and strategic changes accordingly.
\end{abstract}

Dr. Öğr. Üyesi Aşır Özbek, Kırıkkale Üniversitesi Kırıkkale MYO, ozbek@kku.edu.tr 
This study deals with the efficiency analysis of a charity organization called "Beşinci Mevsim Yardım Derne$\breve{g} i$, operating in Kirıkkale since 2004. The model used in the study involves using two different methods integrally (Data Envelopment Analysis (DEA) and Efficiency Analysis Technique with Output Satisficing (EATWOS)), and comparing the results. The input and output weights used in the model were calculated by scoring technique. The findings indicate that this charity organization showed a lower performance in 2007 and 2011 than in the other years.

Keywords: Non Governmental Organizations, Charity Organizations, Efficiency Analysis, Data Envelopment Analysis, EATWOS

\section{Giriş}

Organizasyonlar faaliyetlerini sürdürürken kendilerini belirli aralıklarla verimlilik analizine tabi tutarak aksayan yönlerini düzeltme sürecine girmeli ve sürekli olarak kendilerini yenilemelidir. Kendilerini sürekli olarak geliştiren ve dönüştüren kurumlar, varlıklarını uzun süre devam ettirebilmektedir. Toplumlarda sosyal dokuyu koruma, refahın iyileştirilmesi ve adil bölüşümü için bağımsız olarak faaliyet gösteren Sivil Toplum Kuruluşları da (STK), kâr amacı güden işletmeler gibi belirli aralıklarla verimlilik analizi yaparak kendilerini yenilemeli ve iyileştirmelidir. Kâr amacı güden işletmelerin, faaliyetlerini sürdürebilmeleri kâr etmelerine bağlı iken hayırsever kuruluşlar (HK) genel olarak ticari faaliyet içerisinde yer almadıklarından, etkinlikleri ve verimlilikleri oranında hayatiyetlerini sürdürebilmektedirler. Aksi takdirde bu tür kuruluşlar faaliyetlerini uzun süre devam ettirmede zorluklarla karşlaşabilmektedir.

STK, belirli bir amacı gerçekleştirmek üzere birçok bireyin bir araya gelerek oluşturdukları, gönüllülük usulüyle çalışan, kâr amacı gütmeyen ve gelirlerini bağışlar ve/veya üyelik ödemeleri ile sağlayan kuruluşlardır. STK'lar, oda, sendika, vakıf ve dernek adı altında faaliyet göstermektedirler (Wikipedia). Küreselleşme ile önemi artan STK'lar, Türkiye'de de son
10 yılda \% 44'lük bir artış göstermiştir. STK'lar; "kâr gütmeyen kuruluşlar", "kâr gütmeyen sektör», "gönüllü kuruluşlar", "hükümet dışı kuruluşlar", "üçüncü sektör", "beşinci kuvvet", "hayırsever yardım kuruluşları" ve "vergiden muaf kuruluşlar" gibi literatürde farklı şekillerde adlandırılmaktadır (trdemarka).

İster kâr amacı gütsün isterse gütmesin tüm organizasyonlar, belirli aralıklarla verimlilik analizleri yaparak aksayan, eksik kalan yönlerini gidermelidir. Kâr amacı gütmeyen organizasyonlar da en az kâr amacı olan işletmeler kadar bu konuyu ciddi olarak ele almalıdır. Çünkü hayırseverlerden toplanan yardımların, toplumun dezavantajlı kısmına ulaşabilmesi ve amaca uygun olarak verimli şekilde kullanılması gerekmektedir. Amaca uygun kullanılmadığı ya da verimsiz faaliyetlerde bulunulduğu görülen HK'lara toplumun ilgisi zamanla azalmaktadır. Bu durumda HK'ların faaliyetlerini amaçları doğrultusunda uzun süre devam ettirmeleri mümkün gözükmemektedir.

$\mathrm{Bu}$ çalışma ile bir HK olan ve Kırıkkale'de sosyal alanlarda, özelliklede ihtiyaç sahiplerine maddi ve manevi destek faaliyetlerinde bulunan «Beşinci Mevsim Yardım Derneğinin» (BMYD) 2005-2014 yılları arasındaki verimliliği, Veri Zarflama Analizi (VZA) ve Efficiency Analysis Technique With Output Satisficing (EATWOS) yöntemlerinden oluşan entegre bir modelle ölçülmüştür. “Toplam Gelir”, "Genel Giderler" ve "Diğer Giderler" girdi, "Amaç ve Hizmet Giderleri Toplamı" ile "Mevcut Kasa ve Banka" ise çıktı faktörleri olarak belirlenmiştir. HK'ların verimlilik ölçümünde bu iki yöntemin bütünleşik olarak kullanıldığı başka bir çalışmaya literatürde rastlanmamıştır. Bu açıdan bu çalışmanın literatüre katkı yapacağı düşünülmektedir.

Çalışmanın akışı şu şekildedir: İkinci bölümde konu ile ilgili literatür taraması yapılmıştır. Üçüncü bölümde VZA ve EATWOS yöntemlerinin teorik yapısı ele alınmış ve bu yöntemlerle yapılan bazı çalışmalara yer verilmiştir. Dördüncü bölümde ise BMYD’nin Dernekler İl Müdürlüğüne verdiği beyannamelerdeki veriler dikkate alınarak 2005-2014 yıllarına ait verimliliği ölçülmüştür. Son bölümde ise yapılan çalışma değerlendirilmiş ve bu konuda gelecekteki araştırmac1lara öneriler sunulmuştur. 


\section{Literatür Taraması}

STK'lar üzerine yapılan literatür taraması göstermiştir ki çalışmaların çoğu STK'ların geçmişi ve faaliyetleri ile ilgili olmaktadır. Literatürde STK'lara ilişkin birçok çalışma olmasına rağmen, bunların verimliliği ile ilgili az sayıda araştırma bulunmaktadır. Buna rağmen STK'larda performans ölçme ve değerlendirme uygulamalarını destekleyen bazı çalışmaları da görmek mümkün olmaktadır (Bouchard, 2009a, b; Eme, 2009).

Kirigia vd. (2004), Kenyadaki Halk Sağlık Merkezlerinin teknik verimliliğini VZA ile ölçmüştür. Gutierrez-Nieto vd. (2007) Bolivya, Kolombiya, Dominik Cumhuriyeti, Ekvator, Meksika, Nikaragua, Peru ve Salvador'da bulunan otuz mikro kredi kurumunun (MKK) verimliliğini sosyal açıdan ve kâr amacı yönünden VZA ile değerlendirilmiştir. Haq (2010), parametrik olmayan VZA yöntemini kullanarak, Afrika, Asya ve Latin Amerika genelinde 39 hükümet dışı mikro kredi maliyetinin verimliliğini ölçmüştür. Lépine vd. (2015), STK'lar tarafından Hindistan'da uygulanan büyük ölçekli HIV önleme projesi «Avahan» in teknik verimlilik belirleyicilerini ortaya çıkarmada; Wijesiri vd. (2015), Sri Lanka'da 36 MKK’nın teknik etkinliğini ölçmede; Widiarto ve Emrouznejad (2015), islami MKK'ları geleneksel MKK'lar ile karşılaştırarak, sosyal ve finansal performansını ölçmede VZA kullanmıştır. Berber vd. (2011), uluslararası yardım kuruluşlarına yapılan bağış verimliliğini değerlendirmede iki aşamalı VZA yöntemini önermiştir. Yeh vd. (1997), toplum temelli gençlik hizmetlerinin etkinliğini; VanderWielen ve Özcan (2015), Virginia'da 48 adet ücretsiz olarak hizmet veren kliniklerin performansını VZA ile ölçmüştür. Özbek (2015a, 2015b), Türk Kizllay'ının 2012-2014 arasındaki verimliliğini ölçmede ve Türkiye kökenli beş STK'nın verimlilik analizinde VZA, EATWOS ve OCRA (Competitiveness Operational Rating) yöntemlerini bütünleşik olarak kullanmıştır. Nanavati (2007), kadınların ekonomik güçlenmesi için çalışan dört STK’nın örgütsel etkinliğini, «mali kaynaklar yönetimi”, «insan kaynakları yönetimi", "hizmet sunumu», «örgütsel profesyonellik", «dış ilişkiler» ve «stratejik yönetim» göstergeleri doğrultusunda ölçmüştür. Ye ve Ge (2009), STK'ların afet kriz yönetimi performansını değerlendirmek için Balanced Scorecard ve hedef programlama yöntemlerini kullanmıştır. Campos vd. (2011), Brezilya'da bazı STK'ların 2007-2009 yıllarındaki performanslarını altı kategoride ve iki aşamalı yürütülen araştırma sonuçlarını karşılaştırmalı analiz yöntemiyle değerlendirmiştir. Arena vd. (2015), sosyal işletmelerin performans ölçümünde kullanabilecekleri kendilerine özgün ölçüm sistemleri tasarımında adım adım yöntemini önermiştir. MacIndoe ve Barman (2012), Boston'da 600 adet STK'nın yöneticisine anket yöntemini uygulayarak STK'ların örgütsel etkinliğini değerlendirmiştirr. Diğer taraftan STK'ların performans ölçümleri ile ilgili çalışmalar arasında; Murray ve Tassie'nin (1994), Fowler (1996), Kaplan (2001), Bagnoli (2009), Greiling (2009), Bagnoli ve Megali (2011), Ebrahim ve Rangan (2011) ve Ramadan ve Borgonovi (2015) tarafından yapılanları da burada saymak mümkündür.

\section{Yöntem}

\section{Veri Zarflama Analizi}

VZA, birden çok farklı ölçü birimlerine sahip girdi ve çıktıların varlığı durumunda karar birimlerinin (KB) göreli etkinliklerini ölçebilen, parametrik olmayan, doğrusal programlama tabanlı bir yöntemidir. Charnes vd. (1978) tarafından ölçeğe göre sabit getiri (constant returns to scale - CRS) varsayımı altında 1978 yllında geliştirilmiş ve CCR (Charnes, Cooper ve Rhodes) olarak adlandırılmıştır. CCR modelinin temel özelliği, KB'lerin birden fazla girdi ya da çıtılarının ağırlıklı bir girdiye ya da çıktıya indirgemesidir. VZA'da temel etkinlik ölçütü, belirli bir KB için çıtıların ağırlıklı toplamlarının girdilerin ağırlıklı toplamlarına bölümüdür (Makni vd, 2015).

VZA'nın, BCC (Banker, Charnes, Cooper) olarak adlandırılan ve ölçeğe göre değişken getiri (variable returns to scale-VRS) temeline dayanan farklı bir modeli, Banker ve arkadaşları tarafından 1984 yılında geliştirilmiştir. CCR, ölçeğe göre sabit getiri varsay1mına dayalı girdi odaklı model olarak KB için kullanılırken, BCC ölçeğe göre değişen getiri varsayımına dayalı çıktı odaklı model olarak niteliksel bilgiyi elde etmek için kullanılmaktadır (Ray, 2004, s.1-11)

VZA'da iki kısıt bulunmaktadır. Birincisi tüm KB'lerin etkinliği l'e eşit ya da l'den küçük olmalıdır ve ikincisi ise girdi-çıktı ağırlıkları pozitif olmalıdır. Belirtilen kısıtlar altında her bir KB için performans skorları elde edilmektedir. Amaç, performans skorunu maksimize eden girdi ve çıktı ağırlıklarının bulunmasıdır. incelenen KB'yi; , $r$ çıktısının ağırlığını; , $i$ girdisinin ağırlığını; ve değişkenleri de sırasıyla $k$. KB’nin $r$ çık- 
tı miktarı ile $i$ girdi miktarını göstermek üzere CCR modeli aşağıdaki şekilde formülüze edilmektedir (Cooper vd., 2011; Özdemir ve Demireli, 2013).

$$
\begin{aligned}
& \operatorname{Max} h_{k}=\sum_{r=1}^{s} u_{r k} y_{r k} \\
& \sum_{r=1}^{s} u_{r k} y_{r k}-\sum_{i=1}^{m} v_{i k} x_{i k} \leq 0 ; \quad j=1,2, \ldots, n \\
& \sum_{i=1}^{m} v_{i k} x_{i k}=1 ; \quad j=1,2, \ldots, n \\
& u_{r k} \geq 1 ; r=1, \ldots, s \\
& v_{i k} \geq 1 ; i=1, \ldots, m
\end{aligned}
$$

\section{EATWOS (Efficiency Analysis Technique With Output Satisficing)}

EATWOS, VZA ve OCRA gibi çıktı ve girdi miktarları arasındaki maksimum getiriyi ölçmenin ötesinde KB’nin optimum çözümler yerine, tatmin edici çözümlere yönelebilmesini destekleyen bir verimlilik analiz yöntemidir. Peters ve Zelewski (2006) tarafın- dan Simon'un "satisficing (tatmin)" kavramını temel alarak 2006 yılında geliştirilen yeni bir tekniktir. "Tatmin" kavramı temelde, karar vericinin, optimal çözümlerden ziyade tatmin edici çözümlere ulaşılması eğiliminde olduğunu tanımlayan bir ifade olmaktadır (Peters ve Zelewski, 2006).

$\mathrm{Bu}$ yöntem, geliştiren yazarlar tarafından ısıl işlem fırınlarının ve tedarik zinciri verimliliğini ölçmede uygulanmıştır (Peters ve Zelewski 2006; Peters vd., 2012). Ayrıca Bansal vd. (2014) tarafından tedarikçilerin değerlendirilmesinde ve Özbek (2015a, 2015b) tarafından ise STK'ların verimlilik analizinde kullanılmıştır.

EATWOS Iş̧lem Adımları (Peters ve Zelewski, 2006) İlk olarak verimlilik analizinin uygulanacağ $\mathrm{KB}^{\prime}$ lerin belirlenmesi gerekmektedir. Daha sonra bu KB'lerin verimlilik analizinde hangi girdi $x_{i k}$ ve çıtı $y_{i j}$ setlerinin dikkate alınacağının tespit edilmesi gerekmektedir. Bu amaçla çıktı seti $y_{i j}$ ve girdi seti $x_{i k}$ kullanılarak aşağıda (3) ve (4) numaralı Eşitliklerde gösterildiği gibi çıktı ve girdi matrisleri oluşturulur.

$\underline{Y}$ matrisinin her sütunu $j$ çıktı değerlerini gösterir-

$$
\underline{Y}=\left[\begin{array}{cccc}
y_{11} & y_{12} & \ldots & y_{1 J} \\
y_{21} & y_{22} & \ldots & y_{2 J} \\
\vdots & \vdots & \vdots & \vdots \\
\vdots & \vdots & \vdots & \vdots \\
\vdots & \vdots & \vdots & \vdots \\
y_{I 1} & y_{I 2} & \ldots & y_{I J}
\end{array}\right]
$$$$
y_{i j} \in R_{\geq 0} \quad \forall i=1, \ldots I, \quad \forall j=1, \ldots, J
$$

ken, her bir satırı da $i$. KB'yi işaret etmektedir.

$$
\underline{X}=\left[\begin{array}{cccc}
x_{11} & x_{12} & \ldots & x_{1 K} \\
x_{21} & x_{22} & \ldots & x_{2 K} \\
\vdots & \vdots & \vdots & \vdots \\
\vdots & \vdots & \vdots & \vdots \\
\vdots & \vdots & \vdots & \vdots \\
x_{I 1} & x_{I 2} & \ldots & x_{I K}
\end{array}\right]
$$

Çıktı matrisi $\underline{X}$ 'de matrisine benzer şekilde Eşitlik (4) kullanılarak oluşturulur.

$$
x_{i k} \in R_{\geq 0} \quad \forall i=1, \ldots I, \quad \forall k=1, \ldots, K
$$


Çıktı matrisine benzer şekilde, girdi matrisi $\underline{X}^{\prime}$ in her sütunu bir girdiye $k(k=1, \ldots, K)$ tekabül ederken, her bir satırı da $i$. KB'ye karşıllı gelmektedir. EATWOS, uygulayıcılara çıktı faktörleri için Tatmin Seviyelerini belirleme imkanı sunmaktadır. Böylece karar verici her bir çıktı $j$ için Tatmin Seviyesi TS belirleme imkanına kavuşmuş olur. Ayrıca EATWOS, çıktı faktörlerinin ve girdi faktörlerinin dış kaynaklı olarak tespit edilen göreli önem ağırlıklarını, değerlendirme sürecine katmayı öngörmektedir. Bu önem ağırlıkları, puanlama tekniği veya Analitik Hiyerarşi Süreci gibi yöntemler kullanılarak da belirlenebilir.

Tatmin Seviyesini Dikkate Almayan EATWOS Yöntemi $\mathrm{Bu}$ seçenek tatmin seviyesini dikkate almayan EATWOS sürümüdür. Tüm çıktı faktörleri için tatmin seviyesi dikkate alınmaz. İlk olarak çıktı seti TOPSIS yönteminde önerildiği şekilde $y_{i j}$ Eşitlik (5a) kullanılarak normalize edilmiştir (Hwang ve Yoon, 1981).

$$
\begin{aligned}
& \exists i \quad \exists j \quad y_{i j} \neq 0: \quad r_{i j}=\frac{y_{i j}}{\sqrt{\sum_{i=1}^{I} y_{i j}^{2}}} \quad \forall i=1, \ldots, I \quad \forall j=1, \ldots, J \\
& \forall i=1, \ldots, I \quad \forall j=1, \ldots, J \quad y_{i j}=0: \quad r_{i j}=0
\end{aligned}
$$

Normalize sürecinin sonucu oluşan normalize edilmiş çıtı matrisi $\underline{R}$ Eşitlik (6) ile gösterilmiştir.

$$
\underline{R}=\left[\begin{array}{cccc}
r_{11} & r_{12} & \ldots & r_{1 J} \\
r_{21} & r_{22} & \ldots & r_{2 J} \\
\vdots & \vdots & \vdots & \vdots \\
\vdots & \vdots & \vdots & \vdots \\
\vdots & \vdots & \vdots & \vdots \\
r_{I 1} & r_{I 2} & \ldots & r_{I J}
\end{array}\right]
$$

İkinci olarak, normalize edillmiş çıktı matrisinin $\underline{R}$ 'nin sütun vektörleri $\vec{r}_{j}$ bazında her çıtı faktörü $j$ için en büyük çıktı değeri olan $r_{j}^{*}$ bulunur.

$$
r_{j}^{*}=\max _{i}\left\{\vec{r}_{j}\right\}
$$

Daha sonra $\underline{R}$ matrisi ve en büyük çıtı değeri olan $r_{j}^{*}$ dikkate alınarak çıktı faktörleri için mesafe boyutları bulunur. Eşitlik (8) bu işlemi göstermektedir.

$$
o p_{i j}=1-\left(r_{j}^{*}-r_{i j}\right) \quad \forall i=1, \ldots, I, \quad \forall j=1, \ldots, J
$$

$r_{i j}$ 'nin $r_{j}^{\text {"' ye olan mesafesi ne kadar azsa } o p_{i j}}$ l'e o kadar yakın olmaktadır. Düşük çıktı miktarına sahip olan KB'ler 0 ile 1 arasında çıktı mesafe boyutlarına sahip olurken, en yüksek çıktı miktarına sahip KB'lerin çıktı mesafe boyutu 1 olmaktadır. Çıktı mesafe boyutları çıtı değerleri olarak ifade edilir.

Bir sonraki adım olarak çıktı miktarlarının normalize edildiği gibi girdi miktarları da (9a) Eşitliği kullanılarak benzer şekilde normalize edilir.

$$
\begin{array}{ll}
\exists i \quad \exists k \quad x_{i k} \neq 0: & s_{i k}=\frac{x_{i k}}{\sqrt{\sum_{i=1}^{l} x_{i k}^{2}}} \quad \forall i=1, \ldots, I \quad \forall K=1, \ldots, K \\
\forall i=1, \ldots, I \quad \forall k=1, \ldots, K \quad x=0: \quad s=0
\end{array}
$$

Daha sonra normalize edilmiş çıktı matrisine benzer şekilde normalize edilmiş girdi matrisi $\underline{S}$ Eşitlik (10)'da gösterildiği gibi oluşturulur.

$$
\underline{S}=\left[\begin{array}{cccc}
S_{11} & S_{12} & \ldots & s_{1 K} \\
S_{21} & S_{22} & \ldots & s_{2 K} \\
\vdots & \vdots & \vdots & \vdots \\
\vdots & \vdots & \vdots & \vdots \\
\vdots & \vdots & \vdots & \vdots \\
s_{I 1} & S_{I 2} & \ldots & s_{I K}
\end{array}\right]
$$


Sonra, normalize edilmiş girdi matrisi $\underline{S}$ nin sütun vektörleri $\overrightarrow{S_{k}}$ vektörü temel alınarak her girdi faktörü $k$ için en küçük girdi değeri olan $S_{k}^{*}$ bulunur.

$$
s_{k}^{*}=\min _{i}\left\{\overrightarrow{s_{k}}\right\} \quad \forall k=1, \ldots, K
$$

Girdiler için mesafe boyutu, $\underline{S}$ matrisinin ilgili değeri olan $s_{i k}$ 'ya 1' eklenir ve normalize edilmiş en küçük girdi miktarı olan $s_{k}^{*}$ çıkarılarak hesaplanır.

$i p_{i k}=1+s_{i k}-s_{k}^{*} \quad \forall i=1, \ldots, I \quad \forall k=1, \ldots, K$

Girdi mesafe boyutları şu şekilde yorumlanmalıdır: $s_{i k}$ 'nın $s_{k}^{*}$ ya olan mesafesi ne kadar küçükse $i p_{i j} 1^{\prime}$ e o kadar yakın olmaktadır. Yüksek girdi miktarına sahip KB'lerin girdi mesafe boyutları yüksek değerlere ulaşırken, düşük girdi miktarına sahip KB'nin girdi mesafe boyutu 1 olmaktadir. Her hangi bir mesafe boyutu $i p_{i k}$ 'nin 0 değeri almaması için 1 eklenmektedir. Çıktı değerine benzer şekilde mesafe boyutu $i p_{i k}$ girdi değeri olarak adlandırılır. Girdi değerleri ve çıktı değerleri her bir KB’nin etkinlik skorunu hesaplamak için kullanılır.

$E_{i}=\frac{\sum_{j=1}^{J} v_{j} * o p_{i j}}{\sum_{k=1}^{K} w_{k} * i p_{i k}} \quad \forall i=1, \ldots, I$

Bir KB’nin düşük verimlik skoru $E_{i}$ diğer KB'lere göre daha düşük verimliliği gösterirken, yüksek verimlilik skoru ise yüksek verimliliğe işaret etmektedir. Böylece, bu etkinlik skorlarına dayanarak, KB'lerin etkinliğinin verimlilik skorları yüksekten düşüğe doğru s1ralayarak bir sıralı dizi $R$ elde edilebilir. $v_{j}$ girdi $w_{k}$ ise çıktı faktörlerinin ağırlıkların göstermektedir.

\section{Tatmin Seviyesini Dikkate Alan EATWOS Yöntemi (Peters \& Zelewski, 2006)}

$\mathrm{Bu}$ aşamada EATWOS yöntemi, en az bir çıktı için “Tatmin Seviyesi” TS dikkate alınarak uygulanır. Tatmin seviyesi belirlenmeyen çıktı faktörlerinin işlemleri bir önceki bölümde gösterildiği gibi yapılır. Tatmin seviyesi kavramı, aşağıda sıralanan mantıksal kuralların EATWOS yöntemine entegre edilmesiyle modellenir: Bu model, Yan vd. (2003) dayanan beş mantıksal kısıtlama içerir. Aşağıdaki verilen mantıksal kisitlamalar (14a, 14b, 15, 16, 17) karar verici tarafından Tatmin seviyesi belirlenen tüm çıktı faktörleri için uygulanır.

$$
\begin{aligned}
& \left(\frac{T S_{j}-y_{i j}}{T S_{j}}\right)+z_{1} \leq 1 \\
& \left(\frac{T S_{j}-y_{i j}}{T S_{j}}\right) * z_{2} \geq 0 \\
& z_{1}, z_{2} \in\{0 ; 1\} \\
& z_{1}+z_{2}=1 \\
& a_{i j}=\frac{y_{i j}}{T S_{j}} * z_{2}+1 * z_{1}
\end{aligned}
$$

Kısıt (14a) ve (14b), $z_{1}$ ve $z_{2}$ mantıksal değişkenlerinin olası değerlerini sınırlamak için kullanılır. Kısıt (15) ile bu mantıksal değişkenler ikili değişkenler olarak tanımlanır. (15) numaralı kısıtla bağlantılı olarak (16) numaralı kısıtın görevi; mantıksal değişkenlerden sadece biri bir değerini alırken diğerinin sıfır değerini almasını sağlamaktır. (17) numaralı kısıtta yer alan mantıksal değişkenlerin olası değerleri (14a), (14b), (15) ve (16) numaralı kisitlar kullanılarak belirlenir .

Eğer ilgili çıktı faktörü için Tatmin Seviyesi TS belirlenmişse, normalize edilmiş çıtıtı miktarları $\alpha_{\mathrm{ij}}$, $(14 \mathrm{a})$, (14b), (15), (16) ve (17) numaralı kisttların uygulanmasıyla elde edilir. Bu çıtı miktarları, normalize edilmiş çıktı matrisi $\underline{A}^{\prime} y ı$ oluşturmak için kullanılır. Bununla birlikte, herhangi bir çıktı $j$ için Tatmin Seviyesi belirlenmemişse, $\underline{A}$ matrisinin ilgili sütun vektörü $\vec{a}_{j}, \underline{R}$ matrisinin $\vec{r}_{j}$ sütun vektörüne eşit olur.

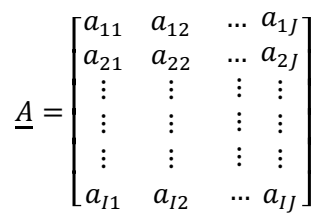

Daha sonra her çıktı faktörü $j$ için en yüksek normalleştirilmiş çıktı miktarı $\alpha_{j}^{*}$, ilgili sütun vektörü $\vec{a}_{j}$ nin en büyük değeri alınarak $\alpha_{j}^{*}$ elde edilir.

$$
a_{j}^{*}=\max _{i}\left\{\overrightarrow{a_{j}}\right\} \quad \forall j=1, \ldots, J
$$

En büyük normalize edilmiş çıtı miktarı $\alpha_{j}^{*}$ çıtı faktörlerinin mesafe boyutunu hesaplamak için kullanılır. Mesafe boyutları tüm KB’ler ve tüm çıktı faktörleri için hesaplanır.

$$
o p_{i j}^{T S}=1-\left(a_{j}^{*}-a_{i j}\right) \quad \forall i=1, \ldots, I \quad \forall j=1, \ldots, J
$$


EATWOS’un daha önceki modelinde olduğu gibi her KB için verimlilik değeri hesaplanır. Ancak bu sefer $E_{i}^{S L}$, çıktı faktörlerinde Tatmin Seviyelerinin dikkate alındığı mesafe boyutlarını $o p_{i j}^{S L}$ temel almaktadır.

$E_{i}^{S L}=\frac{\sum_{j=1}^{J} v_{j} * o p_{i j}^{S L}}{\sum_{k=1}^{K} w_{k} * i p_{i k}} \quad \forall i=1, \ldots, I$

Verimlilik değerlerinin $E_{i}^{S L}$ büyükten küçüğe doğru sıralanmasıyla KB'lerin verimlilik sırası elde edilir.

\section{Uygulama}

Ortaya konan verimlilik modelinde BMYD’nin 20052014 yıllarındaki verimliliği analiz edilmiştir. Modelde girdi faktörleri olarak "Toplam Gelir", "Genel Giderler" ve "Diğer Giderler" ve çıktı faktörleri olarak da "Amaç ve Hizmet Giderleri Toplamı" ile "Mevcut Kasa ve Banka" belirlenmiștir. Modelde kullanılan veriler, BMYD’nin Dernekler İl Müdürlüğüne verdiği beyannamelerden alınmıştır. Veriler aşağıda Tablo l'de gösterilmiştir. Modelin akış şeması aşağıda Şekil. 1'de verilmiştir.
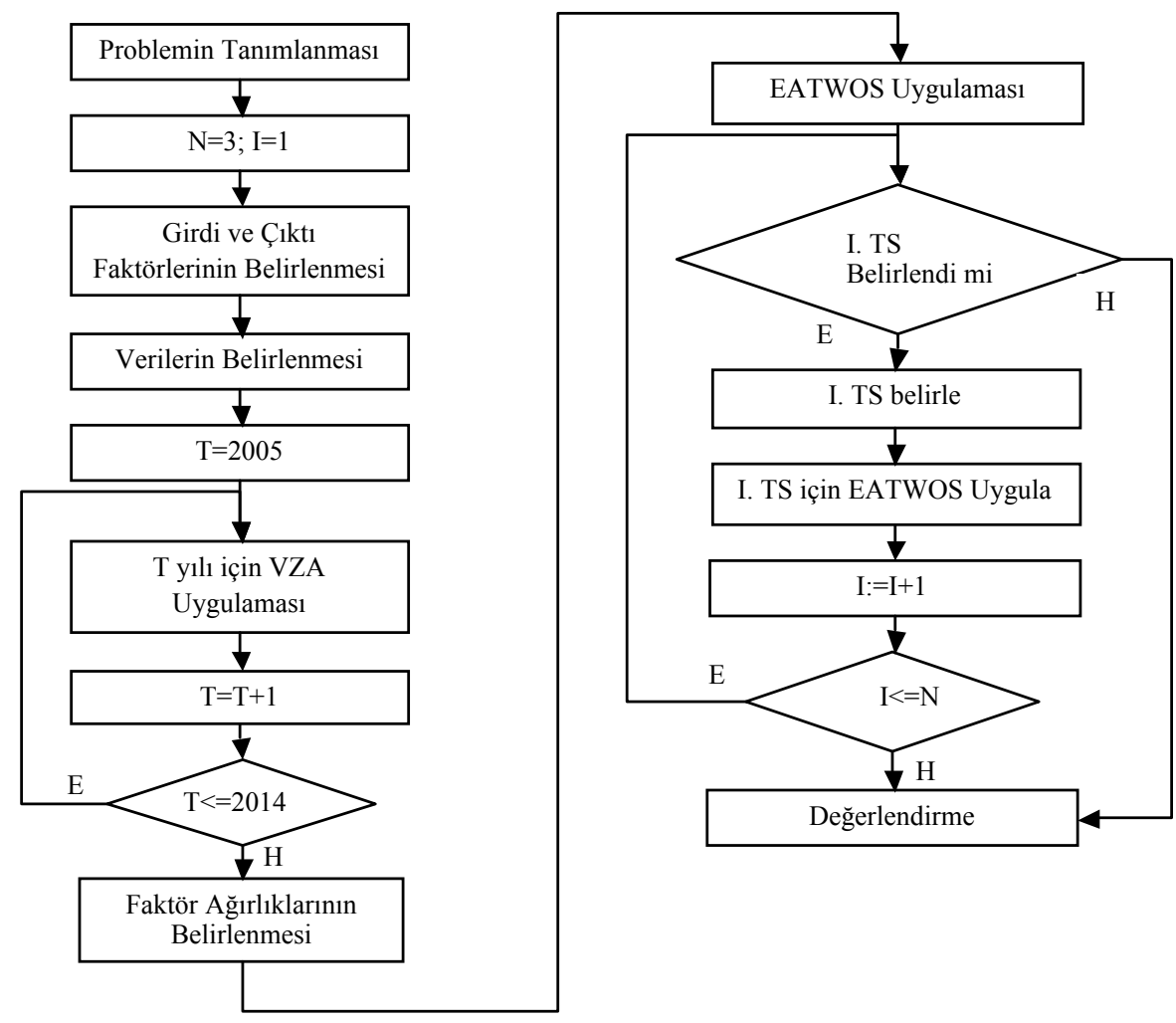

Şekil 1. Modelin işlem Adımları 
Tablo 1. Girdi ve Çıktı Miktarları

\begin{tabular}{|l|r|r|r|r|r|}
\hline \multirow{2}{*}{ Yıllar } & \multicolumn{2}{|c|}{ Çıktılar } & \multicolumn{3}{c|}{ Girdiler } \\
\cline { 2 - 6 } & Amaç ve Hiz. Gid. Top. & Mevcut Kasa ve Banka & Gelir Toplamı & Genel Giderler & Diğer Giderler \\
\hline 2005 & 42.614 & 5.461 & 51.460 & 2.057 & 1.328 \\
\hline 2006 & 38.285 & 31.692 & 74.522 & 2.412 & 2.133 \\
\hline 2007 & 92.235 & 23.670 & 121.505 & 3.001 & 2.599 \\
\hline 2008 & 88.100 & 27.818 & 121.005 & 3.454 & 1.633 \\
\hline 2009 & 88.811 & 29.593 & 113.441 & 2.931 & 106 \\
\hline 2010 & 215.787 & 47.273 & 266.724 & 3.543 & 121 \\
\hline 2011 & 163.900 & 45.491 & 217.219 & 3.689 & 4.139 \\
\hline 2012 & 123.288 & 39.925 & 166.502 & 3.288 & 1 \\
\hline 2013 & 157.655 & 40.744 & 204.267 & 5.867 & 1 \\
\hline 2014 & 137.216 & 47.049 & 188.009 & 3.743 & 1 \\
\hline
\end{tabular}

\section{VZA Uygulaması}

Çalışmada girdiye yönelik ölçeğe göre sabit getirili model kullanılmıştır. Analizler her yıl için ayrı ayrı yapılmıştır. Tablo 1'de verilerin VZA ile analizi neticesinde aşağıda Tablo 2'de gösterilen sonuçlar elde edilmiștir. Sonuçların analizinde șunlar söylenebilir BMYD, 2007, 2008 ve 2011 yllarında faaliyetlerini nispeten verimsiz olarak sürdürürken, 2005, 2006, $2009,2010,2012,2013$ ve 2014 yıllarında verimli olarak devam ettirmiştir.

Tablo 2. VZA Sonuçları

\begin{tabular}{|l|l|l|l|l|l|l|l|l|l|l|}
\hline Yll & $\mathbf{2 0 0 5}$ & $\mathbf{2 0 0 6}$ & $\mathbf{2 0 0 7}$ & $\mathbf{2 0 0 8}$ & $\mathbf{2 0 0 9}$ & $\mathbf{2 0 1 0}$ & $\mathbf{2 0 1 1}$ & $\mathbf{2 0 1 2}$ & $\mathbf{2 0 1 3}$ & $\mathbf{2 0 1 4}$ \\
\hline Skor & 1,000 & 1,000 & 0,949 & 0,925 & 1,000 & 1,000 & 0,975 & 1,000 & 1,000 & 1,000 \\
\hline
\end{tabular}

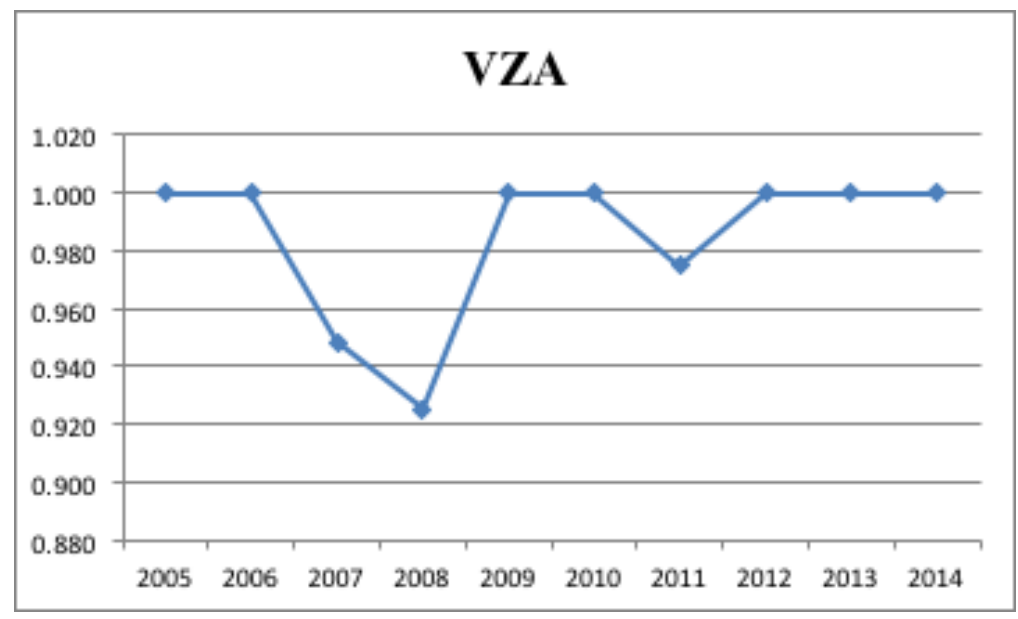

Şekil 2. VZA Verimlilik Grafiği 
Tatmin Seviyesi Belirlenmeyen EATWOS Uygulaması

Tablo 1'de gösterilen veriler kullanılarak EATWOS yöntemi TS belirlenmeden uygulanmıştır. Faktör ağırlıkları şu şekilde belirlenmiştir: Her çıktı faktörünün ağırlığı 0,5 olarak belirlenirken, girdi faktörlerin- den "Gelir Toplamı" için 0,6, "Genel Giderler" ve "Diğer Giderler" faktörlerinin ağırlıkları ise 0,2 olarak belirlenmiştir. (5a) Eșitliği kullanılarak girdi ve çıktı miktarları normalize edilmiștir. Tablo 3'de normalize edilmiş girdi ve çıktı miktarları gösterilmektedir.

Tablo 3. Normalize Edilmiş Girdi ve Çıktı Miktarları Matrisi

\begin{tabular}{|l|c|c|c|c|c|}
\hline \multirow{2}{*}{ Yıllar } & \multicolumn{2}{|c|}{ Çıtılar } & \multicolumn{3}{c|}{ Girdiler } \\
\cline { 2 - 6 } & Amaç ve Hiz. Gid. Top. & Mevcut Kasa ve Banka & Gelir Toplamı & Genel Giderler & Diğer Giderler \\
\hline $\mathbf{2 0 0 5}$ & 0,1066 & 0,0479 & 0,0984 & 0,1840 & 0,2316 \\
\hline $\mathbf{2 0 0 6}$ & 0,0958 & 0,2778 & 0,1425 & 0,2158 & 0,3719 \\
\hline $\mathbf{2 0 0 7}$ & 0,2308 & 0,2075 & 0,2323 & 0,2684 & 0,4532 \\
\hline $\mathbf{2 0 0 8}$ & 0,2204 & 0,2438 & 0,2313 & 0,3090 & 0,2847 \\
\hline $\mathbf{2 0 0 9}$ & 0,2222 & 0,2594 & 0,2169 & 0,2622 & 0,0185 \\
\hline $\mathbf{2 0 1 0}$ & 0,5399 & 0,4144 & 0,5099 & 0,3169 & 0,0211 \\
\hline $\mathbf{2 0 1 1}$ & 0,4101 & 0,3987 & 0,4153 & 0,3300 & 0,7217 \\
\hline $\mathbf{2 0 1 2}$ & 0,3085 & 0,3500 & 0,3183 & 0,2941 & 0,0002 \\
\hline $\mathbf{2 0 1 3}$ & 0,3944 & 0,3571 & 0,3905 & 0,5248 & 0,0002 \\
\hline $\mathbf{2 0 1 4}$ & 0,3433 & 0,4124 & 0,3594 & 0,3348 & 0,0002 \\
\hline
\end{tabular}

Tablo 4. Çıktı ve Girdi Mesafe Boyutları

\begin{tabular}{|l|c|c|c|c|c|}
\hline \multirow{2}{*}{ Yıllar } & \multicolumn{2}{|c|}{ Çıktılar } & \multicolumn{3}{c|}{ Girdiler } \\
\cline { 2 - 6 } & Amaç ve Hiz. Gid. Top. & Mevcut Kasa ve Banka & Gelir Toplamı & Genel Giderler & Diğer Giderler \\
\hline $\mathbf{2 0 0 5}$ & 0,5667 & 0,6335 & 1,0000 & 1,0000 & 1,2314 \\
\hline $\mathbf{2 0 0 6}$ & 0,5559 & 0,8634 & 1,0441 & 1,0318 & 1,3717 \\
\hline $\mathbf{2 0 0 7}$ & 0,6909 & 0,7931 & 1,1339 & 1,0844 & 1,4530 \\
\hline $\mathbf{2 0 0 8}$ & 0,6805 & 0,8295 & 1,1330 & 1,1250 & 1,2846 \\
\hline $\mathbf{2 0 0 9}$ & 0,6823 & 0,8450 & 1,1185 & 1,0782 & 1,0183 \\
\hline $\mathbf{2 0 1 0}$ & 1,0000 & 1,0000 & 1,4115 & 1,1329 & 1,0209 \\
\hline $\mathbf{2 0 1 1}$ & 0,8702 & 0,9844 & 1,3169 & 1,1460 & 1,7215 \\
\hline $\mathbf{2 0 1 2}$ & 0,7686 & 0,9356 & 1,2199 & 1,1101 & 1,0000 \\
\hline $\mathbf{2 0 1 3}$ & 0,8546 & 0,9428 & 1,2921 & 1,3408 & 1,0000 \\
\hline $\mathbf{2 0 1 4}$ & 0,8034 & 0,9980 & 1,2611 & 1,1508 & 1,0000 \\
\hline
\end{tabular}

Eşitlik (7) ve (8) kullanılarak çıktı, Eşitlik (11) ve (12) kullanılarak da girdi mesafe boyutları hesaplanmıştır. Çıktı ve girdi mesafe boyutları Tablo 4'de verilmiştir.
(13) numaralı Eşitlik kullanılarak girdi ve çıktı mesafe boyutları kullanılarak her bir KB için verimlilik skorları elde edilmiştir. Verimlilik skorları Tablo 5'de, grafiksel gösterim ise Şekil 3'de verilmiştir. 
Tablo 5. Yıllara Göre Verimlilik Skorları

\begin{tabular}{|l|l|l|l|l|l|l|l|l|l|l|}
\hline & $\mathbf{2 0 0 5}$ & $\mathbf{2 0 0 6}$ & $\mathbf{2 0 0 7}$ & $\mathbf{2 0 0 8}$ & $\mathbf{2 0 0 9}$ & $\mathbf{2 0 1 0}$ & $\mathbf{2 0 1 1}$ & $\mathbf{2 0 1 2}$ & $\mathbf{2 0 1 3}$ & $\mathbf{2 0 1 4}$ \\
\hline EATWOS & 0,5736 & 0,6410 & 0,6247 & 0,6499 & 0,7004 & 0,7827 & 0,6800 & 0,7384 & 0,7227 & 0,7590 \\
\hline
\end{tabular}

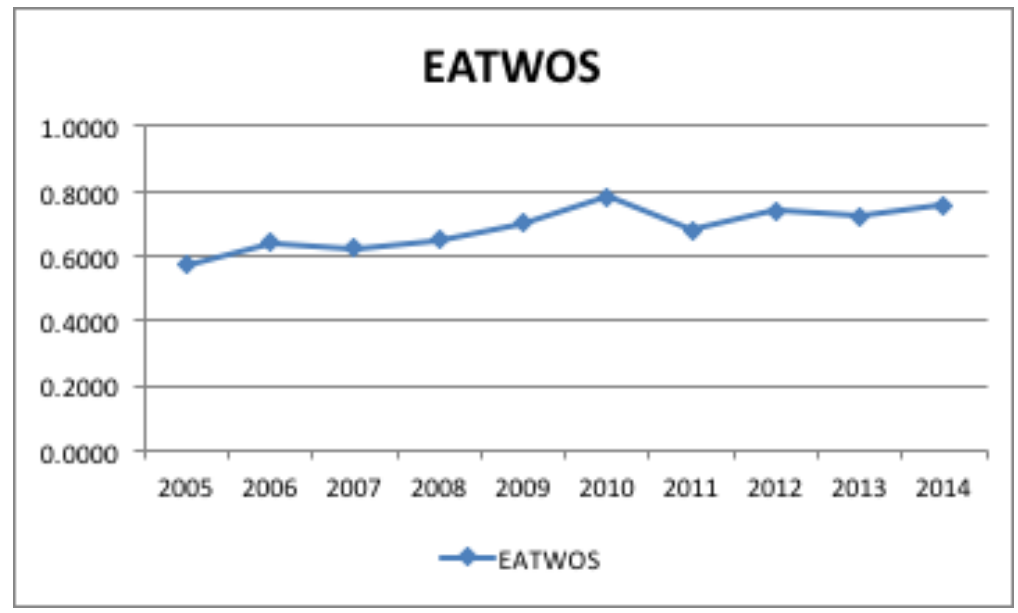

Şekil 3. EATWOS Verimlilik Grafiği

Tablo 5'de verilen sonuçlar ve Şekil 3'de gösterilen grafik birlikte analiz edildiğinde BMYD'nin en iyi performansı 2010 yılında gösterdiği anlaşılmıştır. 2012, 2013 ve 2014 yıllarında da dikkat çekici bir performans sergilediği de görülmektedir. 2011 yılı dikkate alınmadığı takdirde, 2005-2014 yılları arasında verimliliğinin sürekli olarak arış eğilimi gösterdiğini söylemek mümkündür.
Tatmin Seviyesi Belirlenen EATWOS Uygulaması

Tablo 1'de gösterilen veriler temel alınarak 2005 yılı için "Amaç ve Hizmet Giderleri Toplamı" çıktı faktörü için TL ve "Mevcut Kasa ve Banka" çıtı faktörü içinse olarak belirlenmiştir. Ve bu değerler TÜİK'in belirlediği enflasyon rakamları oranında artırılarak her yıl için yeni belirlenmiştir. Çıktı faktörleri (14a), (14b), (15), (16) ve (17) numaralı Eşitlikler kullanıla-

Tablo 6. TS Dikkate Alınarak Hesaplanan Normalize Edilmiş Girdi ve Çıktı Miktarları Matrisi

\begin{tabular}{|l|c|c|c|c|c|}
\hline \multirow{2}{*}{ Yıllar } & \multicolumn{2}{|c|}{ Çıtılar } & \multicolumn{3}{c|}{ Girdiler } \\
\cline { 2 - 6 } & Amaç ve Hiz. Gid. Top. & Mevcut Kasa ve Banka & Gelir Toplamı & Genel Giderler & Diğer Giderler \\
\hline $\mathbf{2 0 0 5}$ & 0,8523 & 0,1612 & 0,2316 & 0,1066 & 0,0479 \\
\hline $\mathbf{2 0 0 6}$ & 0,7108 & 0,8686 & 0,3719 & 0,0958 & 0,2778 \\
\hline $\mathbf{2 0 0 7}$ & 1,0000 & 0,5917 & 0,4532 & 0,2308 & 0,2075 \\
\hline $\mathbf{2 0 0 8}$ & 1,0000 & 0,6415 & 0,2847 & 0,2204 & 0,2438 \\
\hline $\mathbf{2 0 0 9}$ & 1,0000 & 0,6201 & 0,0185 & 0,2222 & 0,2594 \\
\hline $\mathbf{2 0 1 0}$ & 1,0000 & 0,9298 & 0,0211 & 0,5399 & 0,4144 \\
\hline $\mathbf{2 0 1 1}$ & 1,0000 & 0,8410 & 0,7217 & 0,4101 & 0,3987 \\
\hline $\mathbf{2 0 1 2}$ & 1,0000 & 0,2941 & 0,0002 & 0,3085 & 0,3500 \\
\hline $\mathbf{2 0 1 3}$ & 1,0000 & 0,5248 & 0,0002 & 0,3944 & 0,3571 \\
\hline $\mathbf{2 0 1 4}$ & 1,0000 & 0,3348 & 0,0002 & 0,3433 & 0,4124 \\
\hline
\end{tabular}


rak normalize edilmiștir. TS dikkate alınarak normalize edilmiş girdi ve çıktı miktarları Tablo 6'da verilmiştir.
Eşitlik (19) ve (20) kullanılarak çıktı mesafe boyutları ve Eşitlik (11) ve (12) kullanılarak da girdi mesafe boyutları hesaplanmıștır. Girdi ve çıktı mesafe boyutları Tablo 7’de verilmiștir.

Tablo 7. TS Dikkate Alınarak Hesaplanan Çıktı ve Girdi Mesafe Boyutları

\begin{tabular}{|l|c|c|c|c|c|}
\hline \multirow{2}{*}{ Yıllar } & \multicolumn{2}{|c|}{ Çıktılar } & \multicolumn{3}{c|}{ Girdiler } \\
\cline { 2 - 6 } & Amaç ve Hiz. Gid. Top. & Mevcut Kasa ve Banka & Gelir Toplamı & Genel Giderler & Diğger Giderler \\
\hline $\mathbf{2 0 0 5}$ & 1,0000 & 1,0000 & 1,2314 & 0,5667 & 0,6335 \\
\hline $\mathbf{2 0 0 6}$ & 0,8903 & 1,0318 & 1,3717 & 0,5559 & 0,8634 \\
\hline $\mathbf{2 0 0 7}$ & 1,0000 & 1,0844 & 1,4530 & 0,6909 & 0,7931 \\
\hline $\mathbf{2 0 0 8}$ & 1,0000 & 1,1250 & 1,2846 & 0,6805 & 0,8295 \\
\hline $\mathbf{2 0 0 9}$ & 1,0000 & 1,0782 & 1,0183 & 0,6823 & 0,8450 \\
\hline $\mathbf{2 0 1 0}$ & 1,0000 & 1,1329 & 1,0209 & 1,0000 & 1,0000 \\
\hline $\mathbf{2 0 1 1}$ & 1,0000 & 1,1460 & 1,7215 & 0,8702 & 0,9844 \\
\hline $\mathbf{2 0 1 2}$ & 1,0000 & 1,1101 & 1,0000 & 0,7686 & 0,9356 \\
\hline $\mathbf{2 0 1 3}$ & 1,0000 & 1,3408 & 1,0000 & 0,8546 & 0,9428 \\
\hline $\mathbf{2 0 1 4}$ & 1,0000 & 1,1508 & 1,0000 & 0,8034 & 0,9980 \\
\hline
\end{tabular}

Tablo 8. EATWO-TS Yıllara Göre Verimlilik Skorları

\begin{tabular}{|l|l|l|l|l|l|l|l|l|l|l|}
\hline & $\mathbf{2 0 0 5}$ & $\mathbf{2 0 0 6}$ & $\mathbf{2 0 0 7}$ & $\mathbf{2 0 0 8}$ & $\mathbf{2 0 0 9}$ & $\mathbf{2 0 1 0}$ & $\mathbf{2 0 1 1}$ & $\mathbf{2 0 1 2}$ & $\mathbf{2 0 1 3}$ & $\mathbf{2 0 1 4}$ \\
\hline EATWO-TS & 0,7806 & 0,7920 & 0,7548 & 0,7874 & 0,8460 & 0,7827 & 0,7276 & 0,8387 & 0,7812 & 0,8418 \\
\hline
\end{tabular}

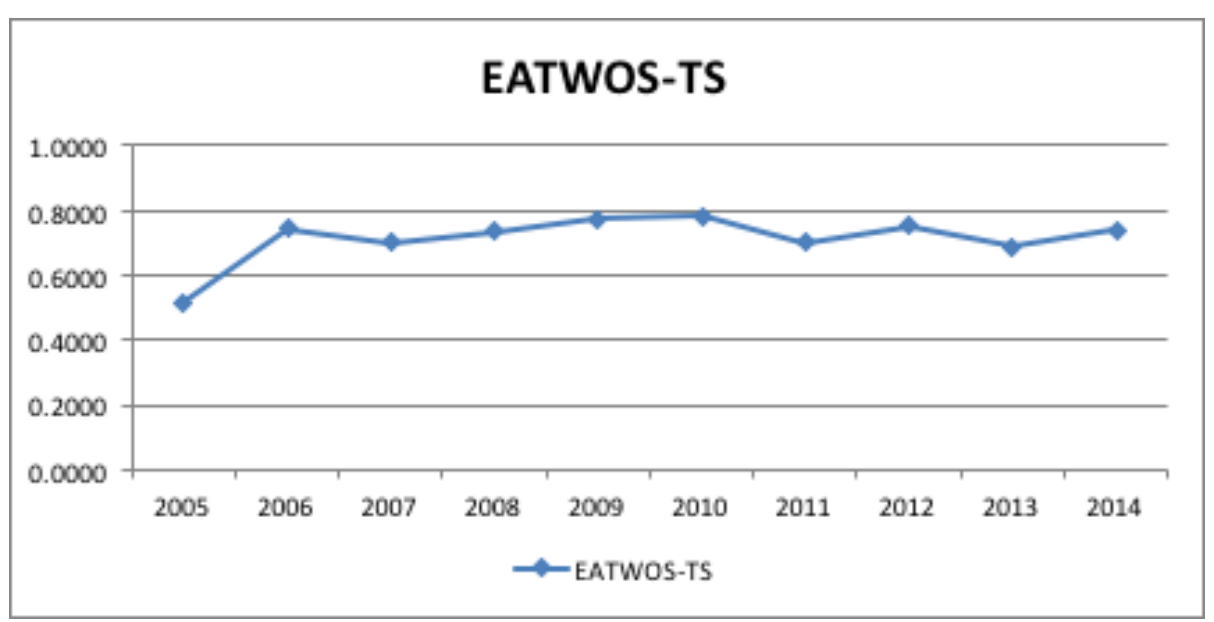

Şekil 4. EATWOS-TS Verimlilik Grafiği 
Her bir KB için verimlilik skorları (21) numaralı Eşitlik kullanılarak girdi ve çıtı mesafe boyutlarından elde edilmiştir. Verimlilik skorları Tablo 8'de ve grafiksel gösterim ise Şekil 4'de verilmiştir.

Tablo 8'de verilen sonuçlar ve Şekil 4'de gösterilen grafik birlikte değerlendirildiğinde, BMYD’nin en iyi performansı 2010 yılında gösterdiği anlaşılmaktadır. 2007-2010 yılları arasında artan verimlilikten söz edilebilirken, 2010-2014 yılları arasında verimliliğin inişli çıkışlı bir grafik izlediği anlaşılmaktadır.
Yapılan analizler neticesinde oluşan verimlilik değerleri toplu olarak Tablo 9'da gösterilmiştir. Tablo 9 ve Şekil 5'de gösterilen grafik birlikte değerlendirildiğinde; 2010 yılının her üç yönteme göre de en yüksek verimin alındığ 1 yl olduğu anlaşılmaktadır.2011 yılının ise yine her üç yönteme göre diğer yllara nispeten verimsiz olduğu görülmektedir. Yine her üç yönteme göre BMYD’nin 2006 yilından itibaren performansı düşüş eğilimine girmesine rağmen, 2008 yılından itibaren toparlanarak tekrar artış eğilimine girdiği görülmektedir.

Tablo 9. Modelin Verimlilik Skorları

\begin{tabular}{|l|l|c|c|}
\hline & VZA & EATWOS & EATWOS-TS \\
\hline $\mathbf{2 0 0 5}$ & 1,0000 & 0,5736 & 0,5179 \\
\hline $\mathbf{2 0 0 6}$ & 1,0000 & 0,6410 & 0,7450 \\
\hline $\mathbf{2 0 0 7}$ & 0,9486 & 0,6247 & 0,6995 \\
\hline $\mathbf{2 0 0 8}$ & 0,9254 & 0,6499 & 0,7367 \\
\hline $\mathbf{2 0 0 9}$ & 1,0000 & 0,7004 & 0,7751 \\
\hline $\mathbf{2 0 1 0}$ & 1,0000 & 0,7827 & 0,7827 \\
\hline $\mathbf{2 0 1 1}$ & 0,9749 & 0,6800 & 0,7007 \\
\hline $\mathbf{2 0 1 2}$ & 1,0000 & 0,7384 & 0,7532 \\
\hline $\mathbf{2 0 1 3}$ & 1,0000 & 0,7227 & 0,6886 \\
\hline $\mathbf{2 0 1 4}$ & 1,0000 & 0,7590 & 0,7418 \\
\hline
\end{tabular}

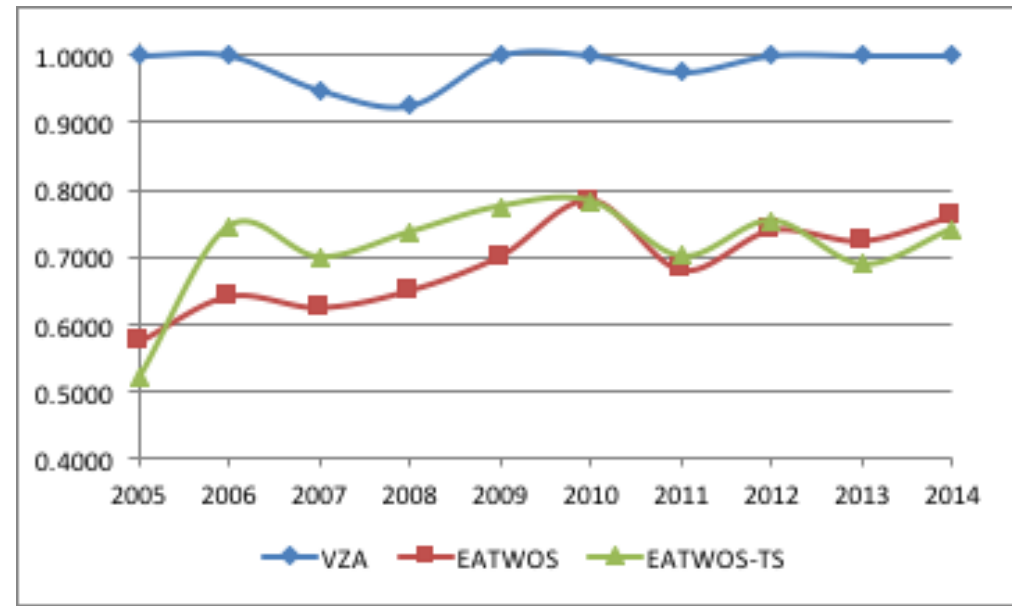

Şekil 5. Modelin Verimlilik Grafiği 


\section{Sonuç}

İşletmeler gibi kâr amacı gütmeyen HK’ lar da verimli çalışmak durumundadır. Verimsiz olarak faaliyetlerini sürdürmeye çalışan HK'lar toplum nezdinde itibar kaybı yaşamakta ve bunun sonucu olarak da varlıklarını uzun süre devam ettirmekte zorlanmaktadır. $\mathrm{Bu}$ ve diğer nedenlerden dolayı HK'lar düzenli olarak verimlilik analizi yaparak zamanında gerekli yönetsel ve stratejik kararları almak durumundadır.

Bu çalışma ile Kırıkkale'de 2004 yılından bu tarafa özellikle hayır işlerinde faaliyetlerini sürdüren BMYD’nin 2005-2014 yıllarındaki verimliliği analizi yapılmıştır. Analizde kullanılan girdi faktörleri “Toplam Gelir", "Genel Giderler" ve «Diğer Giderler» den oluşmaktadır. "Amaç ve Hizmet Giderleri Toplamı" ve "Mevcut Kasa ve Banka" ise çıktı faktörlerini oluşturmuştur. Belirlenen faktörler temelinde VZA, EATWOS ve EAYWOS-TS yöntemleri kullanılarak verimlilik analizi yapılmıştır. Yapılan analizler neticesinde her üç yönteme göre de 2010 yılının en başarılı yıl olduğu belirlenmiştir. 2011 yllının ise yine her üç yönteme göre diğer yıllara nispeten verimsiz olduğu anlaşılmıştır. Yine her üç yönteme göre BMYD’nin 2006 yılından itibaren performansında düşüş eğilimi görülmesine rağmen, 2008 yılından başlayarak tekrar performans artışı eğilimine girdiği görülmektedir. Derneğin ilk yılları olan 2005 ve 2006 yılları faaliyetlerinin kisitlı olmasina rağmen VZA yöntemine göre verimli olarak değerlendirilirken, EATWOS ve EATWOS-TS yöntemlerine göre ise ileriye doğru bir verimlilik artış trendinin olduğu anlaşılmaktadır. 2014-2015 yılları bütün olarak değerlendirildiğinde BMYD’nin verimli olarak faaliyetlerini sürdürdüğünü söylemek mümkündür.

$\mathrm{Bu}$ ve benzeri alanlarda ileride yapılacak çalışmalarda; girdi ve çıktı faktörleri değiştirilerek STK’ların verimlilik analizleri yapılabilir. Ayrıca modelde kullanılan yöntemler TOPSIS vb. çok ölçütlü karar verme yöntemleriyle entegre edilebilir. Bulanık mantık teorisi ile faktörlerin ağılıkları belirlenebilir. Model farklı girdi ve çıktı faktörleri kullanılarak farklı alanlarda yapılacak verimlilik analizi çalışmalarında uygulanabilir.

\section{Kaynakça}

Arena, M., Azzone, G., Bengo, I. (2015). Performance Measurement for Social Enterprises. VOLUNTAS: International Journal of Voluntary and Nonprofit Organizations, 26(2), 649-672. DOI 10.1007/ s11266-013-9436-8

Bagnoli, L. (2009). Performance measuring in social enterprises. Second EMES International Conference on Social Enterprise, Trento.

Bagnoli, L., Megali, C. (2011). Measuring performance in social enterprises. Nonprofit and Voluntary Sector Quarterly, 40(1), 149-165. DOI: 10.1177/0899764009351111

Bansal, A., Kr. Singh, R., Issar, S., Varkey, J. (2014). Evaluation of vendors ranking by EATWOS approach. Journal of Advances in Management Research, 11(3), 290-311. http://dx.doi.org/10.1108/ JAMR-02-2014-0009

Berber, P., Brockett, P. L., Cooper, W. W., Golden, L. L., Parker, B. R. (2011). Efficiency in fundraising and distributions to cause-related social profit enterprises. Socio-Economic Planning Sciences, 45(1), 1-9. DOI:10.1016/j.seps.2010.07.007

Bouchard, J. M. (2009a). The worth of the social economy. In J. M. Bouchard (Ed.). The worth of the social economy: An international perspective (pp. 11-18). Brussels: P.I.E. Peter Lang.

Bouchard, J. M. (2009b). The evaluation of the social economy in Quebec, with regards to stakeholders, mission and organizational identity. In J. M. Bouchard (Ed.), The worth of the social economy: An international perspective (pp.111-132). Brussels: P.I.E. Peter Lang.

Campos, L., Andion, C., Serva, M., Rossetto, A., Assumpção, J. (2011). Performance evaluation in non-governmental organizations (NGOs): An analysis of evaluation models and their applications in Brazil. VOLUNTAS: International Journal of Voluntary and Nonprofit Organizations, 22(2), 238258. DOI: 10.9790/487X-17237076 
Charnes, A., Cooper, W.W., Rhodes, E. (1978). Measuring the efficiency of decision making units. Eur. J. Oper. Res. 2, 429-444. DOI:10.1016/03772217(78)90138-8

Cooper, W. W., Seiford, L. M., Zhu, Joe. (2011). Handbook on data envelopment analysis. NY: Springer. Economic Review, 69(4), 493-513.

Ebrahim, A., Rangan, V. K. (2011). Performance measurement in the social sector: a contingency framework. Social Enterprise Initiative, Harvard Business School, working paper.

Eme, B. (2009). Miseries and worth of the evaluation of the social and solidarity-based economy: For a paradigm of communicational evaluation. In J. M. Bouchard (Ed.), The worth of the social economy: An international perspective (pp. 63-86). Brussels: P.I.E. Peter Lang.

Fowler, A. (1996). Assessing NGO performance: difficulties, dilemmas and a way ahead. Beyond the magic bullet: NGO performance and accountability in the post-Cold War world, 169-187.

Greiling, D. (2009). Performance Measurement in Nonprofit-Organisationen. Springer-Verlag.

Gutierrez-Nieto, B., Serrano-Cinca, C., Molinero, C. M. (2007). Microfinance institutions and efficiency. Omega, 35(2), 131-142. DOI:10.1016/j.omega.2005.04.001

Haq, M., Skully, M., Pathan, S. (2010). Efficiency of microfinance institutions: A data envelopment analysis. Asia-Pacific Financial Markets, 17(1), 6397. DOI: 10.1007/s10690-009-9103-7

http://www.trdemarka.com/MakaleDetay.aspx?i=22 9\&Name $=\% \mathrm{C} 3 \% 9 \mathrm{C} \% \mathrm{C} 3 \% \mathrm{~A} 7 \% \mathrm{C} 3 \% \mathrm{BCnc} \% \mathrm{C} 3 \%$ BC\%20Sekt\%C3\%B6r:\%20Sivil\%20Toplum\%20 Kurulu\%C5\%9Flar\%C4\%B1 (Erişim Tarihi: 16.12.2015)

https://tr.wikipedia.org/wiki/Sivil_toplum_ kurulu\%C5\%9Fu. (Erişim Tarihi: 21.07. 2015)
Hwang, C.-L., Yoon, K. (1981). Multiple Attribute Decision Making - Methods and Applications - A State-of-the-Art Survey. Berlin, Heidelberg, New York 1981, p. 128

Kaplan, R. S. (2001). Strategic performance measurement and management in third sector organizations. Nonprofit Management and Leadership, 11(3), 353-371.

Kirigia, J. M., Emrouznejad, A., Sambo, L. G., Munguti, N., Liambila, W. (2004). Using data envelopment analysis to measure the technical efficiency of public health centers in Kenya. Journal of Medical Systems, 28(2), 155-166. DOI: 10.1023/B:JOMS.00 00023298.31972.c9

Lépine, A., Vassall, A., Chandrashekar, S. (2015). The determinants of technical efficiency of a large scale HIV prevention project: application of the DEA double bootstrap using panel data from the Indian Avahan. Cost Effectiveness and Resource Allocation, 13(1), 5. DOI: 10.1186/s12962-015-0031-2

MacIndoe, H., Barman, E. (2012). How organizational stakeholders shape performance measurement in nonprofits: Exploring a multidimensional measure. Nonprofit and Voluntary Sector Quarterly, 42(4),716-738. DOI: $10.1177 / 0899764012444351$

Makni, R., Benouda, O., Delhoumi, E. (2015). Large scale analysis of Islamic equity funds using a meta-frontier approach with data envelopment analysis. Research in International Business and Finance, 34, 324-337. DOI: 10.1016/j.ribaf.2015.02.014

Murray, V., Tassie, B. (1994). Evaluating the efectiveness of nonprofit organizations. In: Jossey-Bass handbook of nonprofit leadership and management (pp. 303-324). San Francisco: Jossey-Bass.

Nanavati, A. (2007). Performance Evaluation of Nongovernment Development Organisations A Study in Vadodara, Gujarat. Journal of Health Management, 9(2), 275-299. DOI: 10.1177/097206340700900208 
Özbek, A. (2015a). Efficiency Analysis of NonGovernmental Organizations Based in Turkey, International Business Researc,; 8(9), 95-104, http:// dx.doi.org/10.5539/ibr.v8n9p95,

Özbek, A. (2015b). Efficiency Analysis of the Turkish Red Crescent between 2012 and 2014, International Journal of Economics and Finance, 7(9), 322334, http://dx.doi.org/10.5539/ijef.v7n9p322

Özdemir, A., Demireli, E. (2013). Ağırlık Kısıtlı Veri Zarflama Analizi İle Mevduat Bankalarının Etkinlik Ölçümüne Yönelik Bir Uygulama. Uluslararası Yönetim İktisat ve İsletme Dergisi, 9(19), 215-238.

Peters, M. L., Zelewski, S. (2006). Efficiency analysis under consideration of satisficing levels for output quantities. In Proceedings of the 17th Annual Conference of the Production and Operations Management Society (POMS), 28(1.05).

Peters, M. L., Zelewski, S., Bruns, A. S. (2012). Extended Version of EATWOS concerning Satisficing Levels for Input Quantities. Pioneering Supply Chain Design: A Comprehensive Insight Into Emerging Trends, Technologies and Applications, 10, 303.

Ramadan, M. A., Borgonovi, E. (2015). Performance Measurement and Management in NonGovernmental Organizations, IOSR Journal of Business and Management (IOSR-JBM),70-76. DOI: 10.9790/487X-17237076

Ray, S. (2004). Data Envolopment Analysis: Theory and Techniques for Economics and Operations Researh, Cambridge University Press, New York.
VanderWielen, L. M., Ozcan, Y. A. (2015). An Assessment of the Health Care Safety Net Performance Evaluation of Free Clinics. Nonprofit and Voluntary Sector Quarterly, 44(3), 474-486.

Widiarto, I., Emrouznejad, A. (2015). Social and financial efficiency of Islamic microfinance institutions: A data envelopment analysis application. Socio-Economic Planning Sciences, 50, 1-17. DOI: 10.1016/j.seps.2014.12.001

Wijesiri, M., Viganò, L., Meoli, M. (2015). Efficiency of microfinance institutions in Sri Lanka: a twostage double bootstrap DEA approach. Economic Modelling, 47, 74-83. DOI: 10.1016/j.econmod.2015.02.016

Yan, H., Yu, Z., Cheng, T. C. E. (2003). A strategic model for supply chain design with logical constraints: formulation and solution. Computers \& Operations Research, 30(14), 2135-2155. DOI: 10.1016/S03050548(02)00127-2

Ye, Bai-qing, Ge, Tai-ping. (2009). Study on the Disaster Crisis Management Performance Evaluation of Non-governmental Organizations, 5th International Conference on Public Administration, 1, 423427.

Yeh, J., White, K. R., Ozcan, Y. A. (1997). Efficiency evaluation of community-based youth services in Virginia. Community Mental Health Journal, 33, 487-499. 